Original article

\title{
Near-infrared spectroscopy to predict cerebral hyperperfusion after carotid endarterectomy
}

\author{
Ivan N. Shchanitsyn, Igor V. Larin, Roman M. Bakharev, Oleg Yu. Lukin
}

Saratov State Medical University, Saratov, Russia

Received 11 May 2018, Revised 23 August 2018, Accepted 27 August 2018

(C) 2018, Shchanitsyn I.N., Larin I.V., Bakharev R.M., Lukin O.Yu.

(C) 2018, Russian Open Medical Journal

Abstract: The aim: to conduct retrospective study of cerebral regional oxygen saturation (rSO2) at all stages of carotid endarterectomy (CEA) to define ischemia and cerebral hyperperfusion predictors.

Material and Methods - $\mathrm{rSO}_{2}$ were registered in 169 patients under general anesthesia after induction, before carotid artery clamping, 2 minutes after and each 10 minutes after clamping, before, 2 and 5 minutes after reperfusion and at the end of the operation. We estimated baseline values and intraoperative changes of $\mathrm{rSO}_{2}$ in terms of clinical and instrumental findings. Logistic regression analysis was aimed to define significant risk predictors of cerebral ischemia and hyperperfusion and ROC-curve analysis - to set a cut-off point of $\mathrm{rSO}_{2}$ reduction and elevation.

Results - Arterial hypertension III grade (HR 9.5\%; CI 95\%: 1.1-82.7) appeared to be an independent predictor according to the results of multivariate analysis. It was revealed that the most significant predictor of hyperperfusion syndrome is absolute increase of $\mathrm{rSO}_{2}$ after reperfusion by more than 11.3 . Sensitivity, specificity, positive and negative predicative value of the defined parameter were $87.4 \%, 83 \%$, $35 \%$ and $98.4 \%$ respectively.

Conclusion - The conducted multivariate analysis demonstrated that only long-term arterial hypertension is a significant risk factor for hyperperfusion syndrome development after CEA. In our study the most accurate parameter for Fore-Sight oximeter is maximum value of absolute increase in $\mathrm{rSO}_{2}$ after reperfusion by more than 11.3. Cerebral oximetry is a non-invasive method which is easy to use and interpret and enables to estimate both ischemia and cerebral hyperperfusion during CEA and in the early postoperative period.

Keywords: carotid endarterectomy, cerebral oximetry, near-infrared spectroscopy, cerebral hyperperfusion syndrome.

Cite as Shchanitsyn IN, Larin IV, Bakharev RM, Lukin OYu. Near-infrared spectroscopy to predict cerebral hyperperfusion after carotid endarterectomy. Russian Open Medical Journal 2018; 7: e0411.

Correspondence to Ivan N. Shchanitsyn. Tel.: +7 964 8799466. E-mail: dr.green@list.ru.

\section{Introduction}

The incidence of neurological complications after carotid endarterectomy (CEA) occurs in 3-5\% [1, 2]. In most cases perioperative stroke develops as a result of long-term carotid artery clamping, thrombosis or embolization [2-5]. Cerebral hyperperfusion syndrome (CHS) after CEA was reported in $0-12 \%$. Most common methods used for neuromonitoring include electroencephalography, somatosensory evoked potentials, carotid stump pressure, transcranial Doppler (TCD) ultrasound or combinations of these; as well as assessing the development of neurological signs during endarterectomy performed under local anaesthetic [6]. In recent years a lot of studies came out on the use of cerebral oximetry (CO) for neuromonitoring during CEA.

In 1977 Franz Jöbsis gave first description of near-infrared spectroscopy (NIRS) method for estimating blood circulation parameters in myocardial and brain tissue [7]. In 1985 Ferrari et al. reported the use of $\mathrm{CO}$ in humans [8] and in 1993 first commercial cerebral oximetry was maintained by FDA (Food and Drug Administration) in the USA. Nowadays there are several devices of CO: INVOS (Somanetics Corporation, USA), CAS Medical Systems (Branford, USA), Nonin EQUANOX (Nonin Medical Inc., USA),
Critikon Cerebral Redox Monitor (Johnson and Johnson Medical Ltd, USA), TOS (Tostec, Japan), NIRO 300 (Hamamatsu Photonics, Japan), OM220 (Shimadzu Co., Japan), et al. In Russian Federation there are two $\mathrm{CO}$ devices available working on the basis of sourcedetector separated spectroscopy: Fore-Sight (CASMED, USA), Invos (Somanetics, USA).

None of the neuromonitoring methods in CEA demonstrated significant advantage over the others [9]. CO appeared to have high correlation with other monitoring methods and advantages of being a non-invasive, continuous and easily interpreted method. Nevertheless CO allows only for indirect assessment of blood flow in the frontal area of cerebral cortex while injuries of parietal lobe and deep structures cannot be assessed, cut-off points for critical ischemia and hyperperfusion are not yet defined and there are few studies estimating the influence of various clinical and demographic factors on $\mathrm{CO}$ results.

The aim of this study was to conduct retrospective analysis of cerebral regional oxygen saturation at all stages of carotid endarterectomy to define ischemia and cerebral hyperperfusion predictors. 


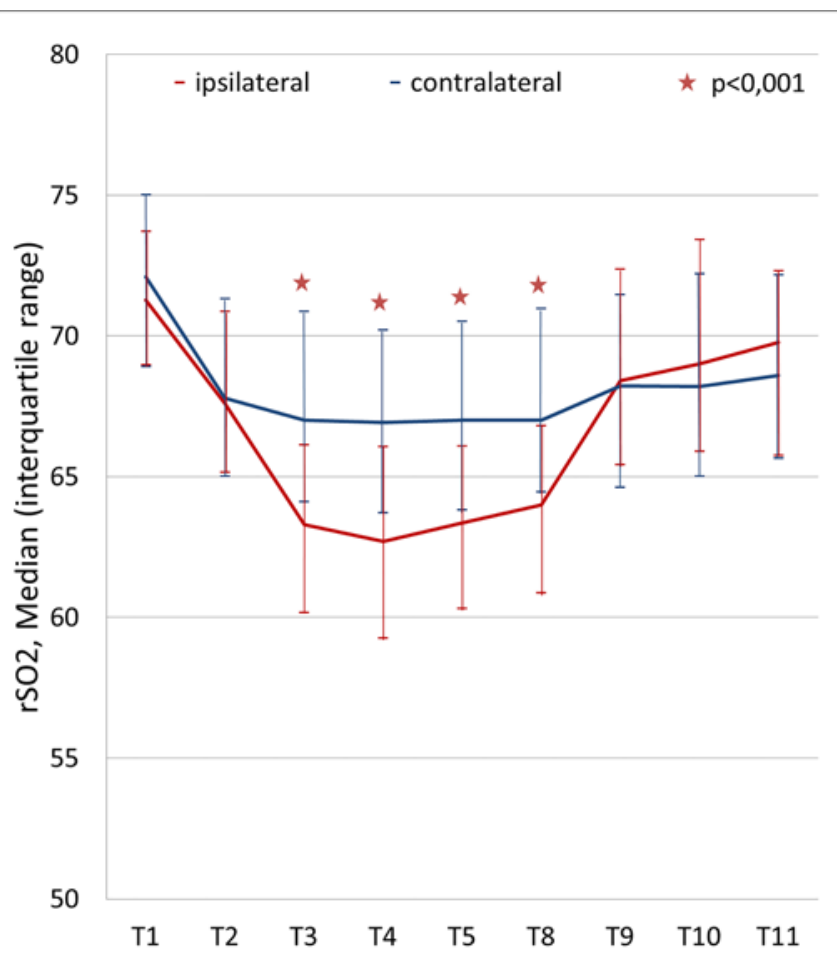

Figure 1. Intraoperative changes in regional cerebral oxygen saturation $\left(\mathrm{rSO}_{2}\right)$ in all patients on the surgical and contralateral side.

\section{Material and Methods}

\section{Patients}

We analysed regional oxygen saturation $\left(\mathrm{rSO}_{2}\right)$ of brain tissue in the course of 169 operations on carotid arteries. All operations were performed in the Department of Neurosurgery of Research Institute of Traumatology, Orthopedics and Neurosurgery of Saratov State Medical University (Saratov, Russia) from February 2013 to November 2017.

\section{Intraoperative technique and monitoring}

All operations were performed under general anaesthesia (fentanyl, propofol). Suxamethonium chloride or pipecuronium bromide in standard dose were given to reach myorelaxation. Mean arterial blood pressure was sustained in the range from $+20 \%$ to $-20 \%$ from the preoperative level with the change of anaesthetic depth. Artificial ventilation was performed in the normoventilation mode with $40 \%$ oxygen to sustain partial carbon dioxide pressure in the $30-36 \mathrm{mmHg}$. Routine monitoring included electrocardiography, indirect measurement of arterial pressure, pulse oximetry and capnography.

In most cases we used standard anterior approach from sternocleidomastoid muscle. Heparin $5000 \mathrm{U}$ was administered five minutes before carotid cross clamping. Eversion carotid endarterectomy (eCEA) was performed in $77.5 \%$ (131/169), eCEA with internal carotid artery (ICA) tortuosity resection - in $7.1 \%$ $(12 / 169)$, endarterectomy from common carotid artery - in 3.5\% (6/169), classical carotid endarterectomy - in $2.4 \%$ (4/169), ICA tortuosity resection in $9.4 \%(16 / 169)$.
During CEA parameters of $\mathrm{rSO}_{2}$ were registered each $20 \mathrm{sec}$. The sensors of cerebral oximeter were applied to the hairless scalp overlying the frontal lobe (cerebral oximeter Fore-Sight, CASMED). Mean values for $1 \mathrm{~min}$. at different stages: after anesthesia (T1), before carotid artery clamping (T2), 2 minutes after (T3) and each 10 minutes after clamping (T4-7), before reperfusion (T8), 2 minutes after (T9) and 5 minutes after (T10) reperfusion and at the end of the operation (T11) were considered in the analysis. We estimated baseline value and analyzed intraoperative changes of $\mathrm{rSO}_{2}$ based on clinical and instrumental findings.

The neurologic status was evaluated before the operation, after awakening and before discharge. CHS was diagnosed in presence of transitory mental disorders and severe cephalgia without any additional ischemic injury on computed tomography (CT) or magnetic resonance imaging (MRI). CT perfusion or single-photon emission CT (SPECT) in postoperative period was not performed.

\section{Statistical analysis}

Statistical analysis was performed using Microsoft Office Excel 13 (Microsoft, USA) and SPSS Statistics 23 (IBM, USA). Data are presented as median and interquartile range - Me ( $L Q, U Q)$.

To calculate the differences between cerebral hyperperfusion (CHS) and non-CHS patients, the Mann-Whitney $U$ test was used. To compare groups for qualitative indexes we used Pearson chisquare test (when total number of observations was less than 5 applied Fisher's exact test). The Wilcoxon signed rank test was used to compare $\mathrm{rSO}_{2}$ changes at different time periods. Differences were deemed statistically significant if $p<0.05$. Logistic regression analysis was used to determine the joint effect of multiple variables on hyperperfusion after CEA. The optimal cutoff points was chosen using the receiver operating characteristic (ROC) curve and Youden's index (sensitivity + specificity -1 ). Variables with $p$-values $<0.2$ from univariate analysis were included in multivariate analysis. Direct step-by-step approach with inclusion probability 0.05 and exclusion 0.10 and more was used. Odds ratio with confidence interval $95 \%$ was calculated. Predictive values are shown as sensitivity, specificity, positive predictive value (PPV) and negative predicative value (NPV), positive likelihood ratio (LR+), negative likelihood ratio (LR-) and diagnostic odds ratio (DOR).

All procedures performed in study were in accordance with the ethical standards of the institutional research committee and with the 1964 Helsinki declaration.

\section{Results}

Changes of $\mathrm{rSO}_{2}$ in all patients on the surgical and contralateral side are shown on Figure 1. Statistically significant reduction of $\mathrm{rSO}_{2}$ level on the operated side during carotid clamping was stated in comparison with contralateral side $(p<0.001)$.

Neurological complications (transitory ischemic attack, TIA) after the operation were present in two patients $(1.2 \%, 2 / 169)$. While estimating the most effective parameter predicting TIA development we revealed several parameters in univariate analysis, however, these parameters did not demonstrate significance in multivariate analysis. $\mathrm{rSO}_{2}$ reduction ipsilaterally 2 minutes after clamping had largest area under the curve (AUC). The defined cut-off 2-min-post-clamping points of more than 9.1 had $100 \%$ sensitivity and $90.4 \%$ specificity. However PPV was only $11.1 \%$ which was associated with rare incidence of complications. 


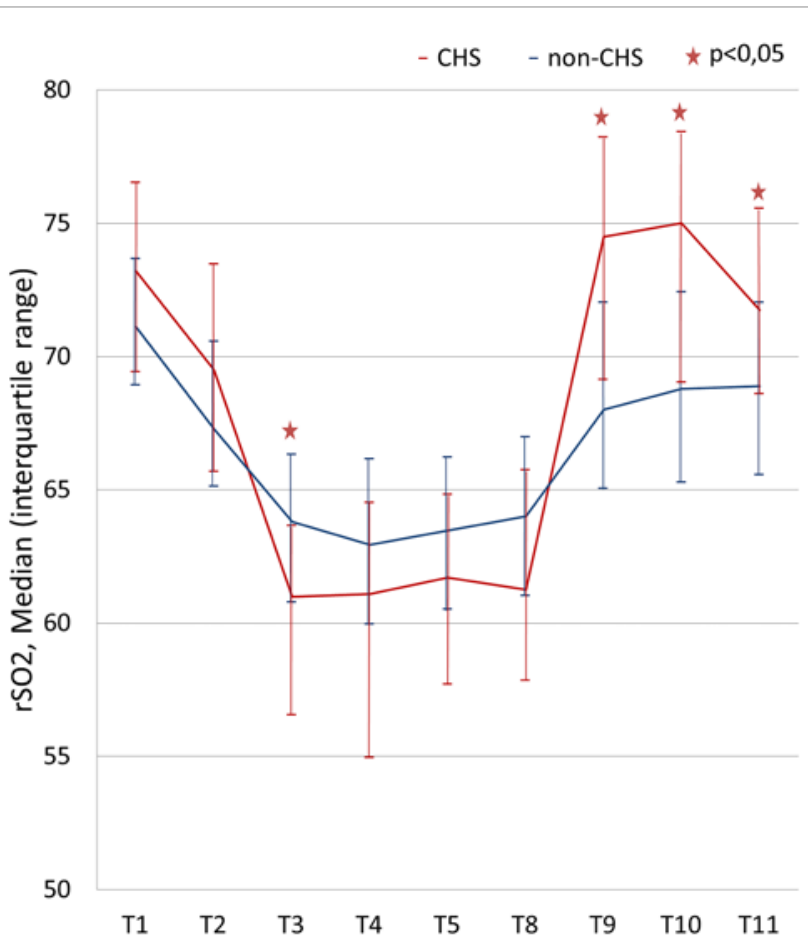

Figure 2. Intraoperative changes in ipsilateral regional cerebral oxygen saturation ( $\mathrm{rSO}$ ) in the cerebral hyperperfusion (CHS) and the noncerebral hyperperfusion (non-CHS) group.

In postoperative period CHS developed in 16 patients $(9.5 \%$, 16/169). 10 patients $(5.3 \%, 9 / 169)$ had severe cephalgia and 6 patients - transitory mental disorders $(2.9 \%, 5 / 169)$. Clinical manifestations of hyperperfusion completely vanished by discharge. In one case $(0.6 \%, 1 / 169)$ there was significant increase of preoperative neurological deficit (aphasia). All patients with signs of hyperperfusion development underwent MRI. There were no signs of additional ischemic brain injury.

Clinical data of 169 patients is presented in Table 1. Figure 2 presents the comparison of $\mathrm{rSO}_{2}$ changes on the surgical side in patients with and without hyperperfusion. Initially before and during clamping $\mathrm{CO}$ results in patients with and without hyperperfusion did not differ ( $p>0.05)$. Significant differences in $\mathrm{rSO}_{2}$ were revealed only 2 minutes after clamping $(\mathrm{p}=0.018)$ and after reperfusion $(p=0.014)$.

Univariate analysis demonstrated that body mass index (BMI) of more than $27 \mathrm{~kg} / \mathrm{m}^{2}$ and arterial hypertension III grade are predictors of hyperperfusion syndrome. However, multivariate analysis specified only long-term arterial hypertension III grade to be an independent predictor (LR 9.5, Cl 95\%: 1.1-82.7). Mean intraoperative arterial blood pressure did not correlate with $\mathrm{rSO}_{2}$ changes.

In order to define the most significant CO parameters allowing to predict hyperperfusion development we conducted multivariate analysis with the specification of cut-off points considering ROCcurves (Table 2). The following parameters appeared to be independent predictors of hyperperfusion: $\mathrm{rSO}_{2}$ value ipsilaterally 5 minutes after reperfusion $>76.5$ ( $L R 7.2, \mathrm{Cl} 95 \%$ : 1.1-45.4), maximum interhemispheric difference $\mathrm{rSO}_{2}$ during clamping $>7.4$ (LR 16.4, Cl 95\%: 2.5-107.3), maximum difference between $\mathrm{rSO}_{2}$ value during clamping and after reperfusion $>11.3$ (LR 15.9, Cl 95\%: 1.6-152.2). The last parameter had the largest AUC and DOR (Table 3).
Table 1. Clinical and instrumental data

\begin{tabular}{|c|c|c|c|}
\hline \multirow[b]{2}{*}{ Variables } & \multicolumn{2}{|c|}{ Hyperperfusion } & \multirow[b]{2}{*}{ P-value } \\
\hline & $\begin{array}{c}\text { No } \\
(n=153)\end{array}$ & $\begin{array}{c}\text { Yes } \\
(n=16)\end{array}$ & \\
\hline \multicolumn{4}{|l|}{ Clinical data } \\
\hline Age, years & $64(58,68)$ & $64(60,70)$ & 0.964 \\
\hline $\mathrm{BMI}, \mathrm{kg} / \mathrm{m}^{2}$ & $28(25,32)$ & $31(28,35)$ & 0.035 \\
\hline Women & $61(40)$ & $8(50)$ & 0.438 \\
\hline Atherosclerosis & $138(90)$ & $15(94)$ & \multirow{2}{*}{0.537} \\
\hline Tortuosity & $15(10)$ & $1(6)$ & \\
\hline Symptomatic patients & $71(46)$ & $8(50)$ & 0.799 \\
\hline $\operatorname{MoCA}(n=73)$ & $23(19,25)$ & $21(19,24)$ & 0.332 \\
\hline CCI (A.V. Pokrovsky): & & & 0.530 \\
\hline-1 & $10(6)$ & $2(12)$ & \\
\hline-11 & $11(7)$ & $2(12)$ & \\
\hline- III & $80(52)$ & $6(37)$ & \\
\hline$-I V$ & $52(34)$ & $6(37)$ & \\
\hline \multicolumn{4}{|l|}{ Comorbidity } \\
\hline Ischemic heart disease & $112(73)$ & $10(62)$ & 0.386 \\
\hline Chronic heart failure & $28(18)$ & $3(19)$ & 0.593 \\
\hline Arrhythmia & $18(12)$ & $2(12)$ & 0.592 \\
\hline Hypertension III degree & $90(59)$ & $15(94)$ & 0.006 \\
\hline Chronic renal failure & $14(9)$ & $3(19)$ & 0.206 \\
\hline Diabetes mellitus & $17(11)$ & $4(25)$ & 0.118 \\
\hline \multicolumn{4}{|l|}{ Instrumental data } \\
\hline Degree of ipsilateral stenosis, $\%$ & $75(70,80)$ & $75(70,80)$ & 0.755 \\
\hline Occlusion & $5(3)$ & 0 & 0.604 \\
\hline Linear velocity of blood flow, $\mathrm{m} / \mathrm{s}$ & $1.8(1.5,2.1)$ & $1.6(1.4,2.0)$ & 0.407 \\
\hline Left side, $\mathrm{n}(\%)$ & $66(43)$ & $7(44)$ & 0.582 \\
\hline Degree of contralateral stenosis: & & & 0.252 \\
\hline$-<50 \%$ & $88(57)$ & $6(37)$ & \\
\hline - >50\% & $60(39)$ & $10(62)$ & \\
\hline - occlusion & $5(3)$ & 0 & \\
\hline Incompleteness of the C.W. $(n=48)$ & $11(25)$ & $1(25)$ & 0.697 \\
\hline \multicolumn{4}{|l|}{ Intraoperative data } \\
\hline Operation time, minutes & $90(80,90)$ & $90(80,94)$ & 0.840 \\
\hline Cross-clamp time, minutes & $31(26,36)$ & $32(25,38)$ & 0.755 \\
\hline Shunt use, $\mathrm{n}(\%)$ & $3(2)$ & $1(6)$ & 0.331 \\
\hline
\end{tabular}

MoCA, the Montreal Cognitive Assessment; $\mathrm{CCl}$, chronic cerebrovascular insufficiency; C.W., Circle of Willis.

Binary data are presented as frequencies and percentages - $\mathrm{n}$ (\%). Continuous data are presented as median with interquartile range - Me (LQ, UQ).

\section{Discussion}

In a meta-analysis of Guay et al. involving 320 patients undergoing CEA (5 studies) sensitivity of cerebral oximetry in revealing ischemia was $74 \%$ (Cl $95 \%$ : 54-89), specificity - $82 \%$ (Cl 95\%: 76-88) [9]. $\mathrm{rSO}_{2}$ cut-off points were in the range of 15$20 \%$. In our study $\mathrm{rSO}_{2}$ reduction 2 minutes after clamping of more than 9.1 had $100 \%$ sensitivity and $90.4 \%$ specificity. However PPV was only $11.1 \%$. Therefore the results of our study should be taken cautiously in the respect of prognostic value of cerebral oximetry in cerebral ischemia and larger cohorts are needed.

Hyperperfusion symptoms include strong headache, convulsions, consciousness disturbances or focal neurological signs in absence of additional ischemic injury on CT or MRI. It is manifested by cerebral oedema, intracerebral hemorrhage as well as increased asymmetrical blood flow in ipsilateral cerebral hemisphere on CT-perfusion or SPECT [13] and TCD [14]. Although the incidence of intracerebral hemorrhage is only $0.4-1.8 \%$ [13], considering increased risk of lethality and neurological deficit the significance of timely diagnostics and treatment of this syndrome is undoubtable. Furthermore, even subclinical hyperperfusion syndrome after CEA may result in cognitive disorders $[10,13]$. 
Table 2. Significant predictors of postoperative hyperperfusion. Univariate and multivariate analysis

\begin{tabular}{|c|c|c|c|c|c|c|}
\hline \multirow[t]{2}{*}{ Variables } & \multicolumn{3}{|c|}{ Univariate analysis } & \multicolumn{3}{|c|}{ Multivariate analysis } \\
\hline & $\mathrm{OR}$ & $\mathrm{Cl} 95 \%$ & P-value & OR & Cl $95 \%$ & P-value \\
\hline $\mathrm{rSO}_{2}$ value 2 minutes after reperfusion $>75.7$ & 14 & $4.4-46.1$ & $<0.001$ & & & NS \\
\hline $\mathrm{rSO}_{2}$ value 5 minutes after reperfusion $>76.5$ & 16 & 4.8-52.5 & $<0.001$ & 7.2 & $1.1-45.0$ & 0.035 \\
\hline $\mathrm{rSO}_{2}$ value at the end of the operation $>68.1$ & 6,7 & $1.5-30.6$ & 0.007 & & & NS \\
\hline $\mathrm{rSO}_{2}$ decrease 2 minutes after crossclamping $>5.5$ & 17 & 3.6-76.9 & $<0.001$ & & & NS \\
\hline $\mathrm{rSO}_{2}$ decrease 2 minutes after crossclamping $>8.5 \%$ & 19 & $4.0-84.8$ & $<0.001$ & & & NS \\
\hline The maximum rSO2 decrease during clamping $>7.9$ & 25 & $5.5-117$ & $<0.001$ & & & NS \\
\hline The maximum rSO2 decrease during clamping $>11.6 \%$ & 19 & $5.1-72.4$ & $<0.001$ & & & NS \\
\hline $\mathrm{rSO}_{2}$ increase 2 minutes after reperfusion $>6.0$ & & $*$ & $<0.001$ & & & NS \\
\hline $\mathrm{rSO}_{2}$ increase 2 minutes after reperfusion $>11.8 \%$ & 33 & $7.0-152$ & $<0.001$ & & & NS \\
\hline $\mathrm{rSO}_{2}$-ratio ischemia $<0.885$ & 29 & $6.2-133$ & $<0.001$ & & & NS \\
\hline $\mathrm{rSO}_{2}$-ratio hyperperfusion $>1.184$ & 29 & $6.1-133$ & $<0.001$ & & & NS \\
\hline Interhemispheric $\mathrm{rSO}_{2}$ difference 2 minutes after crossclamping >6.9 & 20 & $5.3-78.2$ & $<0.001$ & & & NS \\
\hline Interhemispheric $\mathrm{rSO}_{2}$ difference 2 minutes after crossclamping $>9.8 \%$ & 17 & 4.5-66.4 & $<0.001$ & & & NS \\
\hline The maximum interhemispheric $\mathrm{rSO}_{2}$ difference during clamping $>7.4$ & 23 & 6.1-87.9 & $<0.001$ & 16 & $2.5-107.0$ & 0.004 \\
\hline The maximum interhemispheric $\mathrm{rSO}_{2}$ difference during clamping $>11.5 \%$ & 21 & $6.2-72.3$ & $<0.001$ & & & NS \\
\hline The maximum interhemispheric $\mathrm{rSO}_{2}$ difference after reperfusion $>6.9$ & 14 & 4.1-46.7 & $<0.001$ & & & NS \\
\hline The maximum difference between $\mathrm{rSO}_{2}$ value during clamping and after reperfusion $>11.3$ & 34 & 7.3-159 & $<0.001$ & 16 & $1.6-152.0$ & 0.016 \\
\hline The maximum difference between $\mathrm{rSO}_{2}$ value during clamping and after reperfusion $>18.4 \%$ & 29 & $6.2-133$ & $<0.001$ & & & NS \\
\hline
\end{tabular}

$\mathrm{rSO}_{2}$, regional cerebrovascular oxygen saturation; OR, odds ratio; $\mathrm{Cl}$, confidence interval; $\mathrm{NS}$, not significant ( $\mathrm{p}>0.05$ ); $\mathrm{SO}_{2}$-ratio ischemia, the lowest $\mathrm{rSO} \mathrm{O}_{2}$ value during clamping divided by the mean $\mathrm{rSO}_{2}$ value before clamping; $\mathrm{SO}_{2}$-ratio hyperperfusion, the highest $\mathrm{rSO}_{2}$ value after reperfusion to the minimum value during clamping.

Variables with $\mathrm{P}<0.2$ from univariate analysis were included in multivariate analysis. ${ }^{*}$ - OR was not calculated when one of the cells in table had a value 2 or less.

Table 3. Diagnostic impact of significant predictors for hyperperfusion syndrome after carotid endarterectomy

\begin{tabular}{|c|c|c|c|c|c|c|c|c|c|}
\hline Variables & $p^{*}$ & $A \cup C$ & $\begin{array}{l}\text { Juden } \\
\text { Index }\end{array}$ & $\begin{array}{c}\text { Cut-off } \\
\text { point }\end{array}$ & Se & $S p$ & $L R+$ & $L R-$ & $D O R$ \\
\hline $\mathrm{rSO}_{2}$ value 5 minutes after reperfusion & 0.002 & 0.74 & 0.44 & 76.5 & 50 & 94 & 8.5 & 0.5 & 16 \\
\hline The max interhemispheric $\mathrm{rSO}_{2}$ difference during clamping & $<0.001$ & 0.86 & 0.66 & 7.4 & 81 & 84 & 5.2 & 0.2 & 23 \\
\hline The max difference between $\mathrm{rSO}_{2}$ value during clamping and after reperfusion & $<0.001$ & 0.88 & 0.71 & 11.3 & 87 & 83 & 5.1 & 0.1 & 34 \\
\hline
\end{tabular}

* - Mann-Whitney U-test. $\mathrm{rSO}_{2}$, regional cerebrovascular oxygen saturation; max, maximum; AUC, area under the curve; Se, sensitivity (in \%); Sp, specificity

(in \%); LR+, positive likelihood ratio; LR-, negative likelihood ratio; DOR, diagnostic odds ratio.

Table 4. The cut-off points for $\mathrm{rSO}_{2}$ value in hyperperfusion syndrome prediction after carotid endarterectomy

\begin{tabular}{|c|c|c|c|c|c|}
\hline \multirow[t]{2}{*}{ Parameters } & \multicolumn{5}{|c|}{ Authors } \\
\hline & Ogasawara et al. & Komoribayashi et al & Matsumoto et al. & Pennekamp et al. & Our study \\
\hline Year & 2003 & 2006 & 2009 & 2012 & 2017 \\
\hline Number & 50 & 89 & 64 & 151 & 169 \\
\hline Operation & CEA & CEA & CAS & CEA & CEA \\
\hline Detection & SPECT & SPECT, TCD & SPECT & TCD & Clinical data, MRI \\
\hline Oximeter & TOS 96 & TOS 96 & INVOS 5100 & INVOS 5100 & FORE-SIGHT MC 2030 \\
\hline Variable & $\begin{array}{l}\Delta \mathrm{rSO}_{2} \text { before clamping } \\
\text { and after reperfusion }\end{array}$ & $\mathrm{SO}_{2}$-ratio & $\begin{array}{l}\Delta \mathrm{rSO}_{2} \text { before and } \\
\text { after procedure }\end{array}$ & $\begin{array}{l}\Delta \mathrm{rSO}_{2} \text { before clamping } \\
\text { and after reperfusion }\end{array}$ & $\begin{array}{l}\text { The maximum } \Delta \mathrm{rSO}_{2} \text { during } \\
\text { clamping and after reperfusion }\end{array}$ \\
\hline Cut-off value & $>5 \%$ & $<0,9$ & $>10 \%$ & $>2 \%$ & $>11,3$ \\
\hline Sensitivity, \% & 100 & 90 & 100 & 100 & 87,4 \\
\hline Specificity, \% & 86,4 & 91,1 & 85,5 & 58 & 83 \\
\hline PPV, \% & 50 & 56,3 & 18,2 & 11 & 35 \\
\hline NPV, \% & 100 & 98,6 & 100 & 100 & 98,4 \\
\hline
\end{tabular}

CEA, carotid endarterectomy; CAS, carotid artery stenting; SPECT, single-photon emission computed tomography; TCD, Transcranial Doppler ultrasound; $\mathrm{PPV}$, positive predictive value; NPV, negative predictive value; $\mathrm{rSO}_{2}$, regional cerebrovascular oxygen saturation difference; $\mathrm{SO}_{2}$-ratio, the lowest $\mathrm{rSO} \mathrm{O}_{2}$ value during clamping divided by the mean $\mathrm{rSO}_{2}$ value in the last 2 minutes before clamping.

In our study 16 patients (9.5\%) had hyperperfusion signs in postoperative period: severe cephalgia, transitory mental disorders and neurological deficit increase without additional ischemic changes and intraoperative hemorrhage on MRI. 73 patients were assessed by Montreal Cognitive Assessment before and 6 months after operation. All patients demonstrated statistically significant improvements $(p<0.001)$. But at the same time there were no significant differences depending on the presence of hyperperfusion ( $p=0.459$ ).

There are only a few studies on risks factors of hyperperfuion syndrome after CEA. Various authors have defined the following risk factors: bilateral ICA stenosis and previous stroke [10], longterm arterial hypertension, high-grade stenosis, insufficient collateral blood circulation, contralateral artery occlusion [15], postoperative hypertension [14], decreased cerebrovascular 
reactivity on preoperative TCD [16]. In our study multivariate analysis proved only log-term arterial hypertension III degree to be an independent predictor (LR 9.5, Cl 95\%: 1.1-82.7).

Intraoperative TCD (linear blood velocity assessment in medial cerebral artery) for hyperperfusion syndrome prediction is described by various authors $[14,17]$. But this method requires requires skilled operators for consistent results, not in all patients it can be applied due to the lack of acoustic window. Transcranial cerebral oximetry has a range of advantages: easy to use, providing continuous real-time information, possible to use in the postoperative period [16]. Only a few authors estimated $\mathrm{rSO}_{2}$ cutoff points for the prediction of cerebral hyperperfusion after reperfusion during CEA $[12,14,16,18]$ (Table 4) These studies are conducted with the use of various oximeter types and hyperperfusion assessment parameters. Our study revealed absolute reperfusion values of $\mathrm{rSO}_{2}$ elevation of more than 11.3 to be the most significant predictor of hyperperfusion. Sensitivity, specificity, positive and negative prognostic value were $87.4 \%$, $83 \%, 35 \%$ and $98.4 \%$, respectively.

We assume that early detection of cerebral hyperperfusion with cerebral oximetry allows for preventive treatment, particularly more precise control of arterial pressure in the postoperative period and of anticoagulation therapy length. We reckon that patients with long-term arterial hypertension and hyperperfusion predictors defined by cerebral oximetry are at high risk of hyperperfusion syndrome and require closer monitoring and arterial pressure control (not higher than $120 \mathrm{mmHg}$ ) for several postoperative days. We routinely used enoxaparin on the first day after operation. But after the consideration of this research results we decided to suspend this therapy in order to prevent hemorrhagic complications. Apart from that we suppose it reasonable to use $\mathrm{CO}$ in the early postoperative period in intensive care unit.

\section{Conclusion}

The multivariate analysis demonstrated that only long-term arterial hypertension III grade is a independent risk factor of hyperperfusion after CEA. At present there are no well-defined predictors of $\mathrm{rSO}_{2}$ changes to predict the development of hyperperfusion. Cut-off points depend on the cerebral oximeter type and the criteria for hyperperfusion on the CO-monitor. Out study report the elevation of absolute $\mathrm{rSO}_{2}$ value after reperfusion compared to the clamping value of more than 11.3 to be the most accurate parameter to predict hyperperfusion when Fore-Sight oximeter is used.

\section{Limitations}

Our study has several limitations. Firstly, we did not apply perfusion CT or TDC for the confirmation of cerebral hyperperfusion. Secondly, patients with significant increase of $\mathrm{rSO}_{2}$ after reperfusion had more aggressive antihypertensive treatment which influenced the study results. 26 patients had elevated $\mathrm{rSO}_{2}$ values of more than 11.3 and at the same time did not have any hyperperfusion signs postoperatively. It significantly reduced specificity and positive prognostic value of cerebral oximetry. Thirdly, cerebral oximeter sensors were applied on the forehead and it only monitored a superficial area of the frontal lobe but perfusion changes in other brain areas might have escaped detection. Nevertheless according to previous research SPECT results demonstrate that hyperperfusion was revealed in the whole ipsilateral hemisphere including controlled frontal lobe [13, $14,16]$. Fourthly, high variability of absolute $\mathrm{rSO}_{2}$ values reduced specificity of hyperperfusion predictors. Relative ratio (percentages of reperfusion to clamping or baseline values) might help to overcome this limitation. And yet taken into account the fact that $\mathrm{rSO}_{2}$ values before clamping and at the end of the operation differed in most patients $(p<0.001)$ we assume that estimation of $\mathrm{rSO}_{2}$ changes after reperfusion in comparison with baseline values is not informative. Cerebral oximeter Fore-Sight (Casmed, USA) with 4 near-infrared laser light waves allows assessing absolute $\mathrm{rSO}_{2}$ values. Moreover, our analysis demonstrated high specificity of absolute $\mathrm{rSO}_{2}$ values. Fifthly, in most cases we did not use intraluminar shunt and cerebral ischemia on the background of long-term ICA clamping may have increased hyperperfusion risk postoperatively. However in our study clamping time did not correlate with hyperperfusion rate postoperatively. This stands with the other researches reporting hyperperfusion and clamping time as non-correlating parameters [16]. $\mathrm{rSO}_{2}$ is also influenced by extracranial blood flow, arterial pressure level, blood oxygen saturation, partial carbon dioxide pressure in gas mixture, bilirubin and hematocrit level [19]. In the present study, all patients had blood saturation level of more than $99 \%$, partial carbon dioxide pressure was sustained on the constant level, blood loss was minimal (50 $\mathrm{ml}$ and less), bilirubin and hemoglobin levels did not correlate with $\mathrm{rSO}_{2}$. Two-detector sensor Fore-Sight provides the exclusion of light reflected from superficial extracranial tissues and the obtained signal contains only brain tissue saturation data. Thus it is slightly possible that these factors had any significant influence on $\mathrm{rSO}_{2}$ measurements.

Conflict of interest: none declared.

\section{Ethical approval}

All procedures performed in study were in accordance with the ethical standards of the institutional research committee and with the 1964 Helsinki declaration.

\section{References}

1. Sardar $P$, Chatterjee $S$, Aronow HD, Kundu A, Ramchand P, Mukherjee D, Nairooz R, Gray WA, White CJ, Jaff MR, Rosenfield K, Giri J. Carotid artery stenting versus endarterectomy for stroke prevention: a metaanalysis of clinical trials. J Am Coll Cardiol 2017; 69(18): 2266-2275. https://doi.org/10.1016/i.jacc.2017.02.053.

2. Naylor AR, Ricco JB, de Borst GJ, Debus S, de Haro J, Halliday A, et al. Editor's choice - Management of atherosclerotic carotid and vertebral artery disease: 2017 clinical practice guidelines of the European Society for Vascular Surgery (ESVS). Eur J Vasc Endovasc Surg 2018; 55(1): 3-81. https://doi.org/10.1016/j.ejvs.2017.06.021.

3. Shchanitsyn IN, Maksyushina TD, Titova YI, Persova EA, Bazhanov SP, Karavaikin PA. Spontaneous recanalization of chronic occlusion of the internal carotid artery. Angiol Sosud Khir 2015; 21(2): 124-135. https://www.ncbi.nlm.nih.gov/pubmed/26035575.

4. Halsey JH Jr. Risks and benefits of shunting in carotid endarterectomy. The International Transcranial Doppler Collaborators. Stroke 1992; 23(11): 1583-1587. https://www.ncbi.nlm.nih.gov/pubmed/1440706.

5. Naylor AR, Evans J, Thompson MM, London NJ, Abbott RJ, Cherryman G, Bell PR. Seizures after carotid endarterectomy: hyperperfusion, dysautoregulation or hypertensive encephalopathy? Eur J Vasc $\begin{array}{llll}\text { Endovasc } & \text { Surg 2003; } & \text { 39-44. }\end{array}$ https://doi.org/10.1053/ejvs.2002.1925.

6. Chongruksut $\mathrm{W}$, Vaniyapong $\mathrm{T}$, Rerkasem $\mathrm{K}$. Routine or selective carotid artery shunting for carotid endarterectomy (and different methods of 
monitoring in selective shunting). Cochrane Database Syst Rev 2014; (6): CD000190. https://doi.org/10.1002/14651858.CD000190.pub3.

7. Jöbsis FF. Noninvasive, infrared monitoring of cerebral and myocardial oxygen sufficiency and circulatory parameters. Science 1977; 198(4323): 1264-1267. https://doi.org/10.1126/science.929199.

8. Ferrari M, Giannini I, Sideri G, Zanette E. Continuous non invasive monitoring of human brain by near infrared spectroscopy. Adv Exp Med Biol 1985; 191: 873-882. https://www.ncbi.nlm.nih.gov/pubmed/3008520.

9. Guay J, Kopp S. Cerebral monitors versus regional anesthesia to detect cerebral ischemia in patients undergoing carotid endarterectomy: a meta-analysis. Can J Anaesth 2013; 60(3): 266-279. https://doi.org/10.1007/s12630-012-9876-4.

10. Beliaev Alu, Usachev Dlu, Lukshin VA, Sazonova OB, Shmigel'skil̆ AV, Podoprigora AE. Syndrome of cerebral hyperperfusion after carotid endarterectomy. Voprosy Neirokhirurgii imeni N.N. Burdenko 2011; 75(3): 31-38. Russian. https://elibrary.ru/item.asp?id=18121858.

11. van Mook WN, Rennenberg RJ, Schurink GW, van Oostenbrugge RJ, Mess WH, Hofman PA, de Leeuw PW. Cerebral hyperperfusion syndrome. Lancet Neurol 2005; 4(12): 877-888. https://doi.org/10.1016/S1474-4422(05)70251-9.

12. Ogasawara K, Konno $H$, Yukawa $H$, Endo $H$, Inoue $T$, Ogawa A. Transcranial regional cerebral oxygen saturation monitoring during carotid endarterectomy as a predictor of postoperative hyperperfusion. Neurosurgery 2003; 53(2): 309-314. https://www.ncbi.nlm.nih.gov/pubmed/12925245.

13. Ogasawara K, Sakai N, Kuroiwa T, Hosoda K, lihara K, Toyoda K, et al. Intracranial hemorrhage associated with cerebral hyperperfusion syndrome following carotid endarterectomy and carotid artery stenting: retrospective review of 4494 patients. J Neurosurg 2007; 107(6): 1130-1136. https://doi.org/10.3171/JNS-07/12/1130.

14. Pennekamp CW, Immink RV, den Ruijter HM, Kappelle $\sqcup$, Ferrier CM, Bots $\mathrm{ML}$, et al. Near-infrared spectroscopy can predict the onset of cerebral hyperperfusion syndrome after carotid endarterectomy. Cerebrovasc Dis 2012; 34(4): 314-321. https://doi.org/10.1159/000343229.

15. Reigel MM, Hollier LH, Sundt TM Jr, Piepgras DG, Sharbrough FW, Cherry KJ. Cerebral hyperperfusion syndrome: a cause of neurologic dysfunction after carotid endarterectomy. J Vasc Surg 1987; 5(4): 628634. https://doi.org/10.1016/0741-5214(87)90231-X.

16. Komoribayashi N, Ogasawara K, Kobayashi M, Saitoh H, Terasaki K, Inoue $\mathrm{T}$, Ogawa A. Cerebral hyperperfusion after carotid endarterectomy is associated with preoperative hemodynamic impairment and intraoperative cerebral ischemia. J Cereb Blood Flow Metab 2006; 26(7): 878-884. https://doi.org/10.1038/sj.jcbfm.9600244.

17. Dalman JE, Beenakkers IC, Moll FL, Leusink JA, Ackerstaff RG. Transcranial Doppler monitoring during carotid endarterectomy helps to identify patients at risk of postoperative hyperperfusion. Eur J Vasc Endovasc Surg 1999; 18: 222-227. https://doi.org/10.1053/ejvs.1999.0846.

18. Matsumoto $S$, Nakahara I, Higashi T, Iwamuro $Y$, Watanabe $Y$, Takahashi $K$, Ando M, Takezawa M, Kira JI. Near-infrared spectroscopy in carotid artery stenting predicts cerebral hyperperfusion syndrome. Neurology 2009; 72(17): 1512-1518. https://doi.org/10.1212/WNL.0b013e3181a2e846.

19. Nielsen HB. Systematic review of near-infrared spectroscopy determined cerebral oxygenation during non-cardiac surgery. Frontiers in Physiology 2014; 5: 93. https://doi.org/10.3389/fphys.2014.00093.

\section{Authors:}

Ivan N. Shchanitsyn - MD, PhD, Cardiovascular Surgeon, Research Institute of Traumatology, Orthopedics and Neurosurgery, Saratov State Medical University, Saratov, Russia. https://orcid.org/0000-0003-0565-5172.

Igor V. Larin - MD, Cardiovascular Surgeon, Research Institute of Traumatology, Orthopedics and Neurosurgery, Saratov State Medical University, Saratov, Russia. https://orcid.org/0000-0001-7979-3071.

Roman M. Bakharev - MD, Nerosurgeon, Research Institute of Traumatology, Orthopedics and Neurosurgery, Saratov State Medical University, Saratov, Russia. https://orcid.org/0000-0002-5395-0996.
Oleg Yu. Lukin - MD, Anesthetist, Research Institute of Traumatology, Orthopedics and Neurosurgery, Saratov State Medical University, Saratov, Russia. https://orcid.org/0000-0002-1658-8529. 